\title{
Does the first job affect current youth working status in Bangladesh?
}

\author{
Chiara Mussida \\ Department of Economic and Social Sciences, \\ Università Cattolica del Sacro Cuore - Campus di Piacenza-Cremona, \\ Piacenza, Italy, and \\ Dario Sciulli \\ Department of Economic Studies, \\ Universita degli Studi Gabriele d'Annunzio Chieti e Pescara, Pescara, Italy
}

1025

First job affect current youth working status

Received 27 April 2020 Revised 28 September 2020 6 November 2020 Accepted 24 November 2020

\begin{abstract}
Purpose - This paper evaluates how the first job when individuals entered the labor market affects the probability of youth being currently employed in formal or informal work in Bangladesh.

Design/methodology/approach - The analysis is based on data from the ILO School-to-Work Transition Surveys. The authors use a full-information maximum likelihood approach to estimate a two-equation model, which accounts for selection into the labor market when estimating the impact of entry status on current work outcomes. The main equation outcome follows a multinomial distribution thus avoiding $a$ priori assumptions about the level of individual's utility associated with each work status.

Findings - The authors find that entering the labor market in a vulnerable employment position (i.e. contributing family work or self-employment) traps into vulnerable employment and prevents the transition to both informal and, especially, formal paid work. This finding holds when accounting for endogeneity of the entry status and it is valid both in the short and in the long run. Young women are less likely to enter the labor market, and once entered they are less likely to access formal paid wok and more likely to being inactive than young men. Low education anticipates the entry in the labor market, but it is detrimental for future employment prospects.

Originality/value - The findings indicate the presence of labor market segmentation between vulnerable and non-vulnerable employment and suggest the endpoint quality of the school-to-work transition is crucial for later employment prospects of Bangladeshi youth.
\end{abstract}

Keywords Bangladesh, Work outcomes, Selection, Informal employment

Paper type Research paper

\section{Introduction}

Work status is a crucial condition in an individual's life that can affect many socioeconomic outcomes, including income, social inclusion, health and well-being. Even though having a job that guarantees an income and employment stability, as well as individual rights, is a desirable achievement, it represents a distant goal for many individuals, especially in developing countries.

These issues appear particularly relevant for young people, who are often relegated to disadvantaged positions in the labor market, despite the increase in their educational level. In fact, the growth of good job opportunities is slower than the expansion of the youth population in developing countries (e.g. McKay et al., 2018).

The importance of decent employment is recognized by the 2030 Agenda of the United Nations (United Nations, 2015) in its Sustainable Development Goals (SDGs). SDG 8 aims to

(C) Chiara Mussida and Dario Sciulli. Published by Emerald Publishing Limited. This article is published under the Creative Commons Attribution (CC BY 4.0) licence. Anyone may reproduce, distribute, translate and create derivative works of this article (for both commercial and non-commercial purposes), subject to full attribution to the original publication and authors. The full terms of this licence may be seen at http://creativecommons.org/licences/by/4.0/legalcode

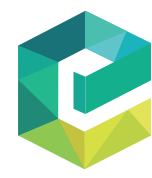

International Journal of Manpower Vol. 42 No. 6, 2021 pp. $1025-1046$

Emerald Publishing Limited $0143-7720$ DOI 10.1108/IJM-04-2020-0175 
IJM

42,6

1026

achieve full and productive employment and decent work for all women and men, including young people, as well as equal pay [1]. Having a decent or formal paid job is not only important for its association with economic growth but also because especially at a young age, it affects important decisions such as marriage and childbearing behaviors and produces spillover effects across society by affecting social and political stability not only in the present but also for future generations (Pieters, 2013).

This article contributes to the study of youth labor market opportunities in developing countries by offering a novel analysis of the role of the first job (when individuals enter the labor market) on later work status. This topic has been little explored in developing countries, where low-quality jobs are widespread, especially among young workers.

Evidence emerging from developed countries suggests that the first job matters for later work patterns; labor market status, in fact, is usually characterized by persistence (e.g. Arulampalam et al., 2000; Millán et al., 2014), which may generate lock-in effects into undesirable work positions (Burgess et al., 2003). The literature offers different scenarios for the consequences of labor market entry positions on future careers, such as the port of entry, stepping-stone and trap hypotheses (Scherer, 2004). According to the port of entry hypothesis (Contini et al., 1999), non-optimal entry positions are transitional steps in the career trajectory and do not entail any negative consequences for one's later career. The stepping-stone hypothesis, instead, denies the existence of negative consequences and predicts that nonoptimal entry positions will bring relative advantages for the subsequent career. The opposite scenario is predicted by the trap hypothesis, which assumes that unsuccessful entry has long-lasting negative consequences for the subsequent work history. These can take place through different mechanisms. One's first job per se is relevant for the acquisition of onthe-job skills to be used in later employment relationships (Green and Montgomery, 1998). Therefore, an individual starting his/her working pattern with a job characterized by poor onthe-job training possibly sends a signal of low productivity to employers and reduces his/her chances of being employed in good jobs in the future. The type of first job also contributes to exacerbating labor market inequality by interacting with educational achievements (Verhaest and Omey, 2013). In addition, Baert et al. (2013) found that accepting a job for which a graduate entering the labor market is overeducated is detrimental for subsequent transition rates into adequate employment. Recently, Manacorda et al. (2017) investigated school-to-work transitions in developing countries and suggest that difficult transitions from school to one's first job lead to worse job matches, which might even translate into worse labor market outcomes in the long run.

When investigating the labor market in developing countries, one has to consider some peculiarities. Unsatisfactory labor market conditions, indeed, are not confined to unemployment and inactivity but include a wide range of employment statuses characterized by vulnerability and informality. Vulnerability is associated with self-employment and contributing family business work, which are usually characterized by lack of formal work arrangements, poor employment protection, difficulties accessing adequate social security and low productivity and earnings (ILO, 2018a). The literature stresses that a significant share of paid work is characterized by informality and, therefore, the concept of informality would be even more relevant than vulnerability when identifying disadvantaged positions in the labor market (Pieters, 2013). Together with the typical problems in detecting and measuring informal jobs, there might also be problems measuring working states. The distinction between paid or unpaid family work and formal or informal jobs, for instance, can be difficult to understand even for those actually doing the job and answering survey questions.

Our guiding hypothesis is that for youths in developing countries, and especially women, there is a trap in unsuccessful entry states that has long-lasting negative consequences for one's subsequent work history. The analysis is conducted by exploiting the School-toWork Transition Survey (SWTS), which provides homogeneous data on individuals aged 
15-29 years in many developing and emerging countries. Importantly, it provides retrospective information about previous work activities, which allows us to identify the first job of an individual and to investigate its effects on his/her current work status.

We focus on individuals living in Bangladesh who entered the labor market at some point in their lives. Analyzing a country pertaining to South Asia is interesting for various reasons. While the Asia-Pacific area shows the highest employment-to-population ratio in the world, in South Asia it remains below the global average, especially because of the weak labor force participation of women. In addition, despite sustained economic growth and increasing employment opportunities, vulnerable employment is widespread in the entire Asia-Pacific region and especially in South Asia, where almost $88 \%$ of workers are informally employed (ILO, 2018a). In this context, the Bangladeshi labor market has remained relatively weak, with relatively low labor market participation (World Bank, 2018), a sustained gender gap and vulnerable employment $(\mathrm{ILO}, 2018 \mathrm{c})$. These characteristics affect the labor market opportunities available for youths, who have faced an increasing unemployment rate in the last decade.

In addition, contrary to what happens in many developing regions, informal employment in Bangladesh is more widespread among women, mainly because of the high proportion of contributing to family workers in this region. Together with social norms, educational attainment, care responsibilities and the lack of employment opportunities (e.g. Sarkar et al., 2019), activities developed in family businesses may contribute to marginalizing women in the informal sector, fostering gender inequality (ILO, 2018a). Therefore, uncovering the later effects of entering the labor market through contributing to family business is important in order to understand the mechanisms leading women to disadvantaged positions in the labor market and preventing their empowerment. Women empowerment, as well as their autonomy and participation in economic and social life, has been recognized as crucial for both their own well-being and for the achievement of SDG 5 [2].

Our empirical approach is based on a two-equation model, which allows accounting for selection into the labor market when estimating the impact of entry status on current work outcomes. The main equation outcome is assumed to follow a multinomial distribution avoiding $a$ priori assumptions about the level of an individual's utility associated with each work status, and then any ex-ante embrace of labor market segmentation or the rational informality thesis [3]. For robustness checks, we also adopt a trivariate model, which allows us to account for the endogeneity of entry status in the main equation. Furthermore, with the aim of uncovering more about gender differences, we offer a supplementary analysis by estimating the model separately by gender.

The paper is structured as follows. Section 2 describes the empirical approach; Section 3 introduces the data, provides a country background and a descriptive analysis; Section 4 presents the estimation results and some robustness checks, while Section 5 offers a discussion and concluding remarks.

\section{Country background}

The Bangladeshi labor market has remained relatively weak compared to other countries of the region, with labor market participation below $60 \%$. In addition, gender inequality [4] is widespread, in terms of both the labor-force participation gap and involvement in contributing family worker activities (World Bank, 2018). These features affect the labor market opportunities of youths, the target population of our work.

The ILO-SWTS data for 2013 (ILO, 2016) show that with the educational level in the country being relatively low, it is not surprising to find that a majority of Bangladeshi employed youths are undereducated for the job they are doing, while only a small fraction are overeducated. The youth unemployment rate stood at $10.3 \%$ in 2013 , which is slightly below the regional average for South Asian countries (11\%). Young women were almost four times as likely to be unemployed than young men. Interestingly, the most disadvantaged in finding
First job affect current youth working status

1027 
IJM

42,6

a job are the young people who attain higher levels of education: the unemployment rate of a youth with primary education was half that of a young secondary graduate, and a fourth that of a young tertiary-educated graduate.

In general, low-quality jobs prevent the country's productive transformation. One of the causes is the relatively young age at which these youths start working. Almost $40 \%$ of youths between 15 and 29 years of age were employed in 2013 (of which $21.8 \%$ were young adolescents from 15 to 17 years of age), with far more men working than young women.

Although more than half of employed youths $(54.6 \%)$ were working as wage and salaried workers, a large share remained in vulnerable employment, as own-account workers $(31.7 \%)$ or unpaid family workers $(11.1 \%)$. At the same time, nearly three-quarters of youths in paid employment were engaged without a written contract (informal paid work).

Youth employment was distributed almost equally between the three main sectors of agriculture, industry and services. Young women were more likely to work in industry than their young male counterparts ( 42.5 and $29.1 \%$, respectively). The relatively high participation of women in industry is partly due to the remarkably rapid growth of the ready-made garment sector in Bangladesh (Heath and Mobarak, 2015). The sector was virtually non-existent in 1980 (Mostafa and Klepper, 2018) but has grown an average of 17\% per year since its inception and now accounts for over $75 \%$ of Bangladesh's export earnings. Around $80 \%$ of garment factory workers in Bangladesh are female (Khatun et al., 2008; Asadullah and Talukder, 2019), and $15 \%$ of young women nationwide between the ages of 16 and 30 work in the garment industry.

Informal employment affected virtually all (95.1\%) young workers in Bangladesh, with similar rates for young men and women (half involving informal employment outside the informal sector and half involving employment in the informal sector).

\section{Methods}

When estimating the impact of one's first job on current work status, we focus on individuals who entered the labor market at a certain point in their lives. Thus, because of partial observability, one has to account for potential endogenous selection to avoid inconsistent estimates. We account for selectivity by running a two-equation model where the selection equation and the work status equation are assumed to follow a bivariate distribution and correlation among error terms is accounted for. The model is jointly estimated by using fullinformation maximum likelihood [5], which produces consistent and fully efficient estimates (Reize, 2001). The advantage of using this model, compared to the standard Heckman approach to selection bias, relies on its flexibility regarding the distributional forms the outcomes may assume. In particular, the work status equation models the probability an individual has one of the five work statuses, i.e. no employment, working in a family business, self-employment, informal paid work and formal paid work. We assume it that follows a multinomial distribution, which means individuals were allowed to choose among alternatives that are not inherently ordered.

The work status equation includes, on its right side, a set of retrospective binary variables, indicating the individual has entered the labor market as a family business worker, self-employed or paid worker, which allows us to measure the impact of the first job on later work outcomes. The selection equation has a binary outcome that takes a value of one if the individual has entered the labor market and zero otherwise. Both equations derive from latent continuous variables and assume normally distributed errors. The specification we adopt to estimate labor market entry is derived from a latent continuous variable $\left(y_{1 i}^{*}\right)$, which is defined at time $t-k$ and is related to a vector of explanatory variables $z$ and an additional variable, $q$, introduced for identification purposes. The corresponding standard linear model can be represented as follows:

$$
y_{1 i}^{*}=z_{i}^{\prime} \alpha+\delta q_{i}+v_{i}
$$


where $\alpha$ is a vector of parameters associated with $z, \delta$ is a parameter associated with the instrument and $v$ is an error term. While $y_{1}^{*}$ is unobserved, $y_{1}$ is observed and related to $y_{1} *$ through the following relationship:

$$
y_{1 i}= \begin{cases}1 & \text { if } y_{1 i}^{*}>0 \\ 0 & \text { otherwise }\end{cases}
$$

Under the normality assumption of the residual $v$, the selection equation is modeled as a probit specification. The latent continuous variable representing the current work outcome propensity $\left(y_{2 \mathrm{ij}}^{*}\right)$ is defined at time $t$ and is related to a set of current explanatory variables $x$ and a set of retrospective binary labor market entry variables $e_{i}$ defined at time $t-k$. The subscripts $i$ and $j$ index individuals and multinomial outcomes, respectively. The corresponding standard linear model reads:

$$
y_{2 \mathrm{ij}}^{*}=x_{\mathrm{ij}}^{\prime} \beta_{j}+\gamma_{j} e_{\mathrm{ij}}+u_{\mathrm{ij}}
$$

$\gamma$ is a set of associated coefficients measuring the impact of one's first job at time $t-k$ on their current work status at time $t . \beta$ is a vector of parameters associated with $x$, and $u$ is an error term. While $y_{2} *$ is unobserved, $y_{2}$ is observed, conditional on $y_{1 i}=1$ and related to $y_{2} *$ through the following general relationship:

$$
y_{2 \mathrm{ij}}=\left\{\begin{array}{l}
j \text { if } y_{2 \mathrm{ij}}^{*}=\max \left(y_{2 i 1}^{*}, y_{2 i 2}^{*}, y_{2 i 3}^{*}, y_{2 i 4}^{*}, y_{2 i 5}^{*}\right), \\
0 \text { otherwise. }
\end{array}\right.
$$

The probability of choosing the category $j$ can be written as:

$$
\begin{aligned}
& \operatorname{Pr}\left(y_{2 \mathrm{ij}}=j \mid x_{i}, e_{i}\right)=\operatorname{Pr}\left(y_{2 \mathrm{ij}}^{*}>y_{2 i 1}^{*}, \ldots, y_{2 \mathrm{ij}}^{*}>y_{2 i 5}^{*}\right) \\
& =\operatorname{Pr}\left(\left(u_{\mathrm{ij}}-u_{i 1}\right)>x_{i}^{\prime}\left(\beta_{1}-\beta_{j}\right)+e_{i}^{\prime}\left(\gamma_{1}-\gamma_{j}\right), \ldots,\left(u_{\mathrm{ij}}-u_{i 5}\right)>x_{i}^{\prime}\left(\beta_{5}-\beta_{j}\right)+e_{i}^{\prime}\left(\gamma_{5}-\gamma_{j}\right)\right) .
\end{aligned}
$$

Under the normality assumption of the residual $u$, the corresponding model is a multinomial probit.

The two-equation system model allows the error terms of equations (1) and (3) to be correlated. Accordingly, we also estimate four correlation terms, $\rho_{v u 2}, \rho_{v u 3}, \rho_{v u 4}$ and $\rho_{v u 5}$, which measure the correlation between the selection equation and the outcomes of the work status equation and provide information about the selectivity process at work in the investigated issues.

Finally, we complement the parameter estimations with average marginal effects (AMEs) [6], which are helpful when interpreting the impact of explanatory variables on outcomes of interest.

\section{Data}

The data used in this paper are from the SWTS [7]. This source covers a representative sample of young people aged from 15 to 29 working in all types of activities.

The SWTS survey was conducted on a largely comparable basis in 36 countries from 2012 to 2015 as part of the Work4 Youth Program coordinated by the ILO and the Mastercard Foundation. The SWTS is implemented through national statistics offices, and most surveys are nationally representative. It collects information on many aspects including personal characteristics and educational status, and very detailed information not just on current 
IJM 42,6

1030

employment but also on the past working history of the individual. This is an added value of this survey [8]. Current and past working history is detailed by information on the characteristics of the jobs, such as the nature of the work, type of contract, sector, payment, working conditions and job satisfaction. From the SWTS, we select data for Bangladesh, which are available for the year 2013.

\subsection{Descriptive analysis}

Table 1 reports the descriptive statistics of the variables used in the selection and current status equations for both the total sample and, for completeness, by gender. The dependent variable for the selection equation is a dummy that equals 1 if the youth made her/his first labor market entry and 0 otherwise. On the selected sample, we estimate the equation for the determinants of the current labor market status that we describe below.

\begin{tabular}{|c|c|c|c|c|c|c|}
\hline & \multicolumn{2}{|c|}{ Total } & \multicolumn{2}{|c|}{ Male } & \multicolumn{2}{|c|}{ Female } \\
\hline & Mean & Std. dev. & Mean & Std. dev. & Mean & Std. dev. \\
\hline \multicolumn{7}{|l|}{ Selection equation } \\
\hline Dependent variable & & & & & & \\
\hline $\begin{array}{l}\text { Entered the labor market } \\
\text { Individual characteristics }\end{array}$ & 0.380 & 0.485 & 0.612 & 0.487 & 0.187 & 0.390 \\
\hline $\begin{array}{l}\text { Female } \\
\text { Age and labor market participation }\end{array}$ & 0.546 & 0.498 & & & & \\
\hline Age of entry or current age $<15$ & 0.361 & 0.480 & 0.362 & 0.480 & 0.360 & 0.480 \\
\hline Age of entry or current age $[15,19]$ & 0.463 & 0.499 & 0.437 & 0.496 & 0.484 & 0.500 \\
\hline $\begin{array}{l}\text { Age of entry or current age > } 19 \\
\text { Education }\end{array}$ & 0.176 & 0.381 & 0.201 & 0.401 & 0.156 & 0.363 \\
\hline $\begin{array}{l}\text { Up to primary education } \\
\text { Parental background }\end{array}$ & 0.375 & 0.484 & 0.407 & 0.491 & 0.348 & 0.476 \\
\hline Father employed & 0.928 & 0.257 & 0.925 & 0.263 & 0.931 & 0.253 \\
\hline Mother employed & 0.081 & 0.273 & 0.086 & 0.281 & 0.076 & 0.265 \\
\hline Father with no education & 0.442 & 0.497 & 0.477 & 0.500 & 0.412 & 0.492 \\
\hline Mother with no education & 0.551 & 0.497 & 0.573 & 0.495 & 0.533 & 0.499 \\
\hline Islam religion & 0.877 & 0.328 & 0.870 & 0.336 & 0.883 & 0.322 \\
\hline Observations & \multicolumn{2}{|c|}{9,121} & \multicolumn{2}{|c|}{4,160} & \multirow{2}{*}{\multicolumn{2}{|c|}{4,961}} \\
\hline \multicolumn{5}{|l|}{ Entry status } & & \\
\hline Contributing family worker & 0.179 & 0.384 & 0.130 & 0.332 & 0.314 & 0.464 \\
\hline Self-employed & 0.275 & 0.447 & 0.315 & 0.464 & 0.167 & 0.373 \\
\hline Paid work & 0.546 & 0.498 & 0.555 & 0.487 & 0.519 & 0.463 \\
\hline $\begin{array}{l}\text { Individual cho } \\
\text { Female }\end{array}$ & 0.269 & 0.443 & & & & \\
\hline Age & & & & & & \\
\hline Aged 15-19 & 0.217 & 0.412 & 0.213 & 0.410 & 0.229 & 0.420 \\
\hline Aged 20-24 & 0.351 & 0.477 & 0.332 & 0.471 & 0.402 & 0.491 \\
\hline Aged 25-29 & 0.432 & 0.495 & 0.455 & 0.498 & 0.369 & 0.483 \\
\hline \multicolumn{7}{|l|}{ Education } \\
\hline Up to primary & 0.548 & 0.498 & 0.567 & 0.496 & 0.496 & 0.500 \\
\hline Working during education & 0.131 & 0.338 & 0.126 & 0.332 & 0.145 & 0.352 \\
\hline Years from first labor market entry & 7.328 & 4.073 & 7.630 & 4.043 & 6.504 & 4.045 \\
\hline Married & 0.541 & 0.498 & 0.478 & 0.500 & 0.713 & 0.453 \\
\hline Bad health & 0.043 & 0.203 & 0.041 & 0.198 & 0.048 & 0.214 \\
\hline Living in rural area & 0.538 & 0.499 & 0.559 & 0.496 & 0.481 & 0.500 \\
\hline Islam religion & 0.884 & 0.321 & \multirow{2}{*}{\multicolumn{2}{|c|}{2,497}} & \multirow{2}{*}{\multicolumn{2}{|c|}{918}} \\
\hline Observations & \multicolumn{2}{|c|}{3,415} & & & & \\
\hline
\end{tabular}

Table 1.

Descriptive statistics by equation (and gender)
Dependent variable

Entered the labor market

Individual characteristics

Female

Age of entry or current age $[15,19]$

Age of entry or current age $>19$

Father employed

Mother employed

ther with no ed

Islam religion

Observations

Current status equation

Entry status

Paid work

Individual characteristics

Age

Aged 15-19

Aged 20-24

Aged 25-29

Education

Years from first labor market entry

Married

Living in rural area

Note(s): Authors' calculations from ILO SWTS data 
Interestingly, from the first row of Table 1 , we note that around $38 \%$ of total youths aged from 15 to 29 years were selected into the labor market. We note a slight prevalence of females in the sample (54.6\%). We consider three dummies for the age of first labor market entry or current age of the youth [9]. When considering the youth entering the labor market, the modal age of entry is less than 15 years (50.3\%), while the percentage of those between 15 and 19 is $37.9 \%$, and the remaining are those over 19 years of age $(11.8 \%)$. We note that $37.5 \%$ of the sample has a low level of education.

We include dummies for parental attitudes toward education. The dummies for education take a value of one if the father and mother have no education and zero for higher educational levels; they capture the impact of no parental education on the labor market entry of young people. In addition, we control for the employment of one's father and one's mother, the latter being introduced for identification purposes since we assume it affects the labor market entry of her children but not their current labor market outcome.

The choice of the instrument was suggested by the existing literature and evidence on developing countries. Women in low- and middle-income countries have had increasing access to employment in the last two decades. The number of working mothers with children was and still is increasing in developing countries (Bongaarts et al., 2019), despite the fact that women's contributions to socio-economic development through their employment would potentially be greater if the incompatibility between their roles as mothers and workers was reduced (ILO, 2018b).

The existing literature on developing countries suggests that women's employment is important for child development in different ways. There is a positive effect of mothers' employment on children, particularly for economic reason. A mother's earnings may contribute to the quality of childcare and provide a healthy daily diet as well as a better (quality of) education for her children. Interestingly, the children of working mothers become independent at home and find it more natural to access the labor market. The presence of a working mother exerts an effect on overall child development, starting from childcare up to the labor market participation of children (Alam and Zanariah, 2012). Mothers' employment therefore affects the entry/access of youths into the labor market. Once entered into the labor market, the effect of a mother's employment weakens, and it is lost in the long run (current labor market status) as other factors, like labor market conditions, labor demand and formal/ informal networks, affect youth labor market opportunities.

The dependent variable for the current (employment) status equation is the current activity status of the youth. We have five outcomes: not employed (unemployed and out of the labor force, including those engaged in domestic work), contributing family business worker, self-employment (essentially, an own-account worker), informal paid employee and formal paid employee. First, we focus our attention on the impact of the type of first job on one's current work status. We indeed control for the entry status of the youth by distinguishing among three types of job: contributing family worker, self-employed and paid work [10].

From the bottom panel of Table 1, we note that there are marked differences in the relative percentages pertaining to the three entry outcomes. Paid employment is the most important entry status for youths ( $54.6 \%$ of the sample), while $27.5 \%$ of the sample is reported as being self-employed and the remaining $17.9 \%$ as unpaid and contributing to a family business. The outcomes also significantly differ by gender. We note that the percentage of female contributing family workers is more than double that of males ( $31.4 \%$ with respect to $13 \%$ ). The opposite is true for self-employment, as the percentage for males is almost double that of females $(31.5 \%$ compared to $16.7 \%)$. We do not find significant gender differences for paid work (55.5\% for males and $51.9 \%$ for females).

We note that only $26.9 \%$ of those working are female. We split the overall bracket into three dummies corresponding to the three age ranges: [15,19], [20,24] and [25,29]. We include dummies for gender, education, and to account for whether the youth worked while studying. 
IJM

42,6

We control for the labor market history of youths by including the number of years since the start of their first job. Interestingly, we find important differences in marital status by gender, as $71.3 \%$ of working females are married with respect to $47.8 \%$ of working males, confirming the increasing participation of women in the labor market, as explained above. Finally, we include dummies for health status, living in a rural area and Islamic faith.

\section{2}

\section{Results}

5.1 Entry employment and current work status

Table 2 reports the average marginal effects that quantify the impact of the first job and controls for the current work status. Non-working status is the base category; therefore, average marginal effects should be interpreted relative to non-working status.

Our estimates suggest that one's first job matters for later work outcomes. Emerging evidence denotes the existence of persistence in a less desirable employment status, since having entered the labor market through vulnerable employment (i.e. contributing family worker or self-employed) increases the probability of currently being in vulnerable employment, with few exceptions. Persistence, however, is more marked for each entering status itself, as an individual having entered the labor market as a contributing family worker is more likely to remain a contributing family worker, while those who entered as selfemployed are more likely to remain self-employed. This finding is partly explained by persistence in the original status, i.e. the case of individuals who have never changed work status since their entry into the labor market.

In addition, we find that the probability of being currently employed in either formal or informal paid work is negatively affected by entering the labor market through vulnerable employment. In particular, having entered the labor market as a contributing family worker appears to be detrimental for the work prospects of individuals as it decreases the probability of accessing better working conditions in the labor market. If one's first job is contributing family work, the probability of being employed in formal paid work decreases by $51.5 \%$. The impact of having entered the labor market as a contributing family worker also affects the probability of reaching a different work status, even though the related magnitude is smaller than the previous ones. Our findings reveal that persistence in contributing family worker status exists, i.e. having entered the labor market in such a status increases the probability of being currently employed in the family business and is very large $(+65.3 \%)$. Interestingly, the probability of currently being self-employed is not affected by entering the labor market as a contributing family worker. Finally, entering the labor market as a contributing family worker decreases the probability of being an informal paid worker $(-36.6 \%)$. The negative impact, however, greatly increases for formal paid work (-51.5\%), suggesting that entering the labor market by working in the family business is generally harmful from a paid work perspective.

The pattern of individuals entering the labor market as self-employed is relatively similar to that displayed by individuals entering as contributing family workers. This is not surprising as own-account workers, which like contributing family workers have vulnerable positions in the labor market, constitute the large majority of self-employed youths in the analyzed countries. Nevertheless, the magnitude related to self-employment is smaller than for contributing family workers, suggesting that the latter is more detrimental than selfemployment for later work perspectives.

Our estimates indicate that when significant, entering the labor market as self-employed increases the probability of being currently employed in a family business (33.9\%). Our results also suggest that persistence in self-employment is particularly strong $(+48.5 \%)$. As mentioned above, entering the labor market as self-employed decreases the probability of being in informal paid work $(-28.9 \%)$. Finally, entering the labor market as self-employed 


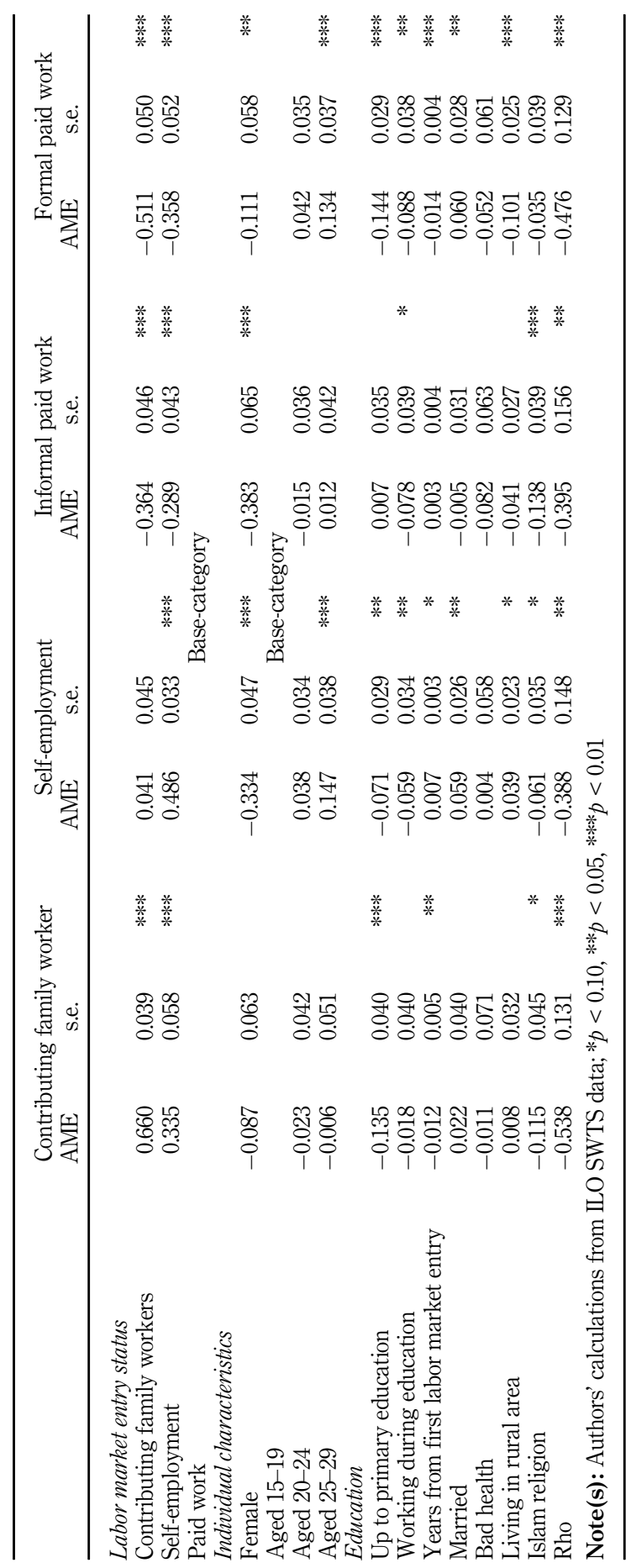

First job affect current youth working status

1033

Table 2.

The impact of employment entry on current work outcomes 
IJM

42,6

1034 decreases the probability of being in formal paid work, and the impact is greater than the impact we find for informal paid work $(-36 \%)$. These results, combined with the previous ones, indicate that vulnerable employment, and particularly contributing family business work, may represent a harmful experience at the beginning of one's working career as it is associated with persistence in vulnerable employment and decreases the chances of being employed in formal paid work. In addition, we do not find evidence of segmentation between formal and informal paid work.

Looking at the individual characteristics included in the model, we note that being female reduces the probability of being employed in all work statuses other than contributing family business worker, suggesting that females are more likely to be marginalized into non-work activities, and if they work they likely work in more disadvantaged employment positions. Young women, as explained above, are almost four times as likely to be unemployed than men. The growth of young female employment in the industry sector due to the remarkable growth of the ready-made garment sector in Bangladesh (Heath and Mobarak, 2015) is not enough to fill the important gender gap in employment.

Age is positively associated with the probability of being employed in both formal paid work and self-employment. Interestingly, a low level of education reduces employment opportunities of youths in all of the outcomes explored other than informal paid work, suggesting that having few skills prevents access to better/decent labor market conditions. Having worked during one's education decreases the probability of currently being selfemployed and employed in both formal and informal paid work. Years since entering the labor market positively affects the probability of being self-employed, while it slightly decreases the probability of being a contributing family worker or formal paid worker. Being married increases the probability of being both self-employed and being a formal paid worker. Bad health does not significantly affect the working status of the analyzed individuals. Living in a rural area increases self-employment but reduces the probability of being employed in formal paid work. Finally, Islamic religion reduces all of the employment probabilities other than informal paid work. This might be due to the fact that, as suggested by the literature (i.e. Ahmed, 2015), Islamic religion is more likely to be associated with low education, and low education decreases the probability of employment.

Rho coefficient estimates suggest that selection exists. However, we estimate a multinomial probit model without taking into account selection, and there are only some slight differences for contributing family workers, while all other parameters remain essentially the same. Table 3 displays the AME for the determinants of selection into labor market entry. In line with the evidence in Bangladesh (see Section 3.1), we note that entry opportunities differ by gender. The dummies for age of first labor market entry or current age are negatively correlated with the labor market entry of youths, while primary education is positively correlated $(+15.3 \%)$.

The presence of an employed mother, which is our instrument, is positively associated with the probability of entering the labor market, while the presence of an employed father does not exert a role on labor market entry. The positive sign of our instrument, as explained above, might be due to the fact that a working mother positively contributes to the development of children from childcare to their independence and first entry into the labor market (for details, see Section 3.2). Nonetheless, the presence of a working mother may increase the possibility that youths work in a family business. While we cannot exclude this possibility, we estimated the model including an interaction between female and marital status. The results are reassuring. The probability of working in a family business is positively associated with married females, while unmarried females are less likely to work in a family business. This suggests that women employed in a family business are those working in a husband's business rather than a mother's business. 


\begin{tabular}{|c|c|c|c|c|}
\hline \multirow[b]{2}{*}{$\begin{array}{l}\text { Individual characteristics } \\
\text { Female }\end{array}$} & $\mathrm{AME}$ & \multicolumn{2}{|l|}{ s.e. } & \multirow{2}{*}{$\begin{array}{l}\text { First job affect } \\
\text { current youth } \\
\text { working status }\end{array}$} \\
\hline & -0.391 & 0.007 & $* * *$ & \\
\hline \multicolumn{5}{|l|}{ Age and labor market participation } \\
\hline Age of entry or current age $[15,19]$ & $\begin{array}{l}\text { Dase-d } \\
-0.129\end{array}$ & 0.011 & $* * *$ & 1025 \\
\hline $\begin{array}{l}\text { Age of entry or current age }>19 \\
\text { Education }\end{array}$ & -0.193 & 0.014 & $* * *$ & Education \\
\hline Up to primary education & 0.153 & 0.011 & $* * *$ & \\
\hline Islam religion & 0.004 & 0.014 & & \\
\hline \multicolumn{5}{|l|}{ Parental background } \\
\hline Father with no education & 0.019 & 0.012 & & \\
\hline Mother with no education & 0.078 & 0.012 & **** & \\
\hline Father employed & 0.010 & 0.018 & & \\
\hline Mother employed & 0.073 & 0.015 & $* * *$ & \\
\hline \multicolumn{4}{|c|}{ Note(s): Authors' calculations from ILO SWTS data; $* * * p<0.01$} & Selection equation \\
\hline
\end{tabular}

As far as parental education is concerned, the presence of a father and, especially, of a mother without education is positively associated with labor market entry. This is in line with expectations. Living in a household where the parents have no education might reduce the attitudes of daughters/sons toward education and simultaneously increase their propensity to enter the labor market. This might be due to the fact that the presence of parents with no education positively affects the (almost immediate) labor market entry of their sons/ daughters.

\subsection{Robustness checks}

We test the robustness of the estimation results presented in Section 4.1 by considering some important checks. First, we account for endogeneity of the entry status by running a trivariate model, that is, the model presented in Section 2 augmented by an equation with a multinomial outcome, which explicitly models the endogenous entry status outcome [11]. Estimates are reported in Appendix 1 (Table A1). They show that the signs of the relationship between entry status and current employment are essentially confirmed, while the magnitude differs in two cases. The persistence into vulnerable employment is smaller than that emerging from the benchmark model, and the negative effect of entering the labor market in a vulnerable employment position on the probability of being in paid work is greater than the effect we estimate by using the benchmark model. In this regard, the estimation from our benchmark model can be considered conservative.

Second, we investigate how the time since entry into the labor market affects the estimates of the entry status variables (Table A2). It cannot be excluded that our findings are dependent on the distribution of the years since entering the labor market; if individuals have recently entered the labor market, it is more likely that they still hold that entry status, while the probability of moving to another employment position should increase overtime. We estimate our benchmark model for three sub-samples: up to five years, from six to ten years and over ten years of experience. We find that the sign and statistical significance of the estimated average marginal effects are in line with those emerging from the main analysis. The magnitude, instead, decreases as the time from entering the labor market increases, in line with our expectations. Nonetheless, the essence of our findings holds both in the short run and in the long run. 
IJM

42,6

1036

As an additional robustness check, we estimate our model for youths from 25 to 29 years of age as in this class, all youths willing to work should have entered the market (Appendix 1 Table A3). We do not find relevant changes in results for persistence of the labor market entry status. The signs and significance of the AMEs remain basically the same.

Finally, as a check with a different outcome variable, we estimate our model by using the outcome job satisfaction; the results were not significant. This might be partly due to the fact that there are different aspects that might influence an individual's job satisfaction [12].

\subsection{Gender analysis}

We provide a supplementary analysis by gender. Differences between males and females remain relevant in Bangladesh, despite the labor market conditions of women having improved in the last decades (see Section 2). The model specification accounting for selection into the labor market is, therefore, applied to gender sub-samples. Estimated average marginal effects are reported in Appendix 2 (Tables A4 and A5 for males and females, respectively) [13]. While the essence of the results is in line with those of the full sample analysis, some relevant differences emerge at the gender level. Persistence in contributing family work, for example, is about $50 \%$ greater for males $(+76.4 \%)$ than for females $(+50.7 \%)$. Among workers who do not persist in the contributing family work status, the most frequent alternative is the transition to inactivity for females and to self-employment for males. In addition, entering the labor market as a contributing family worker reduces by $22.6 \%$ the probability of being in formal paid work for females, while the negative impact is $31.6 \%$ for males. Finally, entering the labor market as a contributing family worker reduces by $56.8 \%$ the probability of being in formal paid work for females, while the negative impact is $39.9 \%$ for males. Entering the labor market as a contributing family worker indeed appears to be more penalizing for women than for men, especially when looking at the way it affects the access to formal work.

Looking at individuals entering the labor market as self-employed, we find that despite self-employment being much more widespread among men, persistence in self-employment is much greater for females $(+73 \%)$ than for males $(+41.4 \%)$, indicating that the former experience greater immobility in that status. In addition, entering the labor market as selfemployed reduces both the probability of being in informal paid work and formal paid work. The negative impact is greater for men $(-32.8 \%)$ than for women $(-17.6 \%)$ when focusing on informal paid work, and greater for women $(-45.4 \%)$ than for men $(-34.3 \%)$ when focusing on formal paid work.

To sum up, our results suggest that entering the labor market in a vulnerable employment position reduces the probability of accessing paid work, both formal and informal. This finding holds for both men and women, but the access to formal paid work is more difficult for women than for men, while the former experience fewer difficulties than men when moving toward informal paid work. In addition, women appear to experience a relatively greater risk of moving toward inactivity when compared to men and show significant persistence in selfemployment.

\section{Discussion and concluding remarks}

Bangladesh is an interesting case study because despite many countries in the same region having recently displayed a successful record of economic performance, the Bangladeshi labor market has remained relatively weak - especially for young women - and is characterized by gender inequality in both labor market participation and in the involvement of contributing family workers. These features become quite relevant for youths first entering the labor market. The existing economic literature suggests that one's first job 
affects later work, and more generally an individual's labor market history, through different and important mechanisms. The first job per se is relevant for the acquisition of on-the-job skills to be used in later employment (Green and Montgomery, 1998), and the type of first job is significantly related to individual educational achievement, as a positive correlation between a high level of education and the probability of a good first job match has emerged (Verhaest and Omey, 2013). Having a decent or formal paid job is not only important for its association with economic growth but also because, especially at a young age, it affects important decisions such as marriage and childbearing behaviors and produces spillover effects across society by affecting social and political stability not only in the present but also for future generations (Pieters, 2013).

Our findings confirm the existing evidence emerging from developed countries that the first job matters for the later working history of youths, as measured by current work outcomes. Interestingly, we find evidence of persistence in the (initial) labor market status, especially in less desirable or vulnerable employment positions like contributing family worker (and self-employment, particularly own-account work).

We note that gender matters. This is shown both by our base model and by the supplementary analysis by gender. In sum, we find that almost $75 \%$ of females in Bangladesh do not enter the labor market, and those who enter are less likely to be employed or trapped in vulnerable employment positions, especially as contributing family workers. Young Bangladeshi women share this condition with those living in some Southern Asian countries (e.g. India and Pakistan) and perform worse than many countries of the nearby South-East (e.g. Cambodia, Thailand, and the Philippines). Interestingly, our findings also suggest that entering the labor market as a contributing family worker is more penalizing for young women than for young men, especially when looking at the way it affects their access to formal work.

Moreover, among workers who do not persist in the contributing family work status, the most frequent alternative is the transition to inactivity for females and to self-employment for males.

Our findings on the impact of first labor market entry on current youth labor market outcomes, as suggested by the existing evidence (e.g. Sparreboom and Staneva, 2014), underline the presence of labor market segmentation in Bangladesh. Even though vulnerable employment may represent an alternative to inactivity, especially for young individuals, entering the labor market as a vulnerable employed worker (especially as a contributing family worker) might be a trap in vulnerable employment and an obstacle to formal employment both in the short and in the long run. In line with the majority of countries of the region, the diffusion of vulnerable employment is associated with moderate or extreme poverty (ILO, 2018c).

We find a role for education and its quality in Bangladesh. On the one hand, the poorly educated are more likely to enter the labor market than young individuals with secondary or tertiary education. This finding matches a pattern common to many countries in the region, indicating a "hollowing out" of middle-skilled jobs in the area and serious problems for the employability of the highly educated (ILO, 2018c). On the other hand, once entered into the labor market, the poorly educated are more likely to experience periods of unemployment and informal employment, while the probability of being in formal paid work is significantly higher for the middle- and highly educated. These findings are in line with expectations and are confirmed by the existing literature (Elder and Kring, 2016; Manacorda et al., 2017). Education might therefore be one of the keys to avoiding unsatisfactory employment positions. From our results, it emerges that investment in both the quality and quantity of education might be a weapon against informal and vulnerable employment and/or bad job matches for young people in developing countries. Nonetheless, the effectiveness of investment in education appears to be conditioned on the growth of demand for skilled jobs,

First job affect current youth working status

1037 
IJM

42,6

which is associated with technological advancements and increasing regional integration, among other things (Asian Development Bank, 2015).

Our findings offer interesting policy suggestions. In particular, they show the importance of improving the quality of school-to-work transitions, but in particular, the effectiveness of this match. Our results also reveal that a good entry in the labor market, besides its positive association with economic growth, is important for future employment prospects and might produce spillover effects across society, affecting social and political stability and future generations.

\section{Notes}

1. For details, see https:/www.undp.org/content/undp/en/home/sustainable-development-goals/goal8-decent-work-and-economic-growth.html.

2. For details, see http://datatopics.worldbank.org/sdgs/sdg-goals-targets.html.

3. The segmentation view suggests that individuals escaping unemployment turn to informal employment once they are unable to find a job in the formal sector (Lewis, 1954; Lehmann and Pignatti, 2018). The integration view suggests that informal employment represents a rational choice for individuals, who gain comparative advantages by being employed in the informal sector rather than in the formal one (Maloney, 2004).

4. Gender difference in early careers is an issue common to many developing countries (see, for instance, Pastore, 2010).

5. Our model is estimated using the routine "cmp" written in STATA by Roodman (2011).

6. We calculate AMEs by following the suggestions of Roodman (2011) even though we acknowledge some limitations, such as the fact that AMEs do not allow us to capture nonlinearity.

7. For details, see http://www.ilo.org/employment/areas/youth-employment/work-for-youth/WCMS_ 191853/lang-en/index.htm.

8. A limitation of the SWTS is that there is no explicit information on the continuity between the first and current job.

9. To define "age of entry or current age", we start by defining the year of entry or potential entry, that is, the year of first economic activity or the current year for those currently at school. Age of entry is obtained from the difference between the year of entry and the year of birth.

10. Retrospective information on one's first job does not allow us to distinguish between formal and informal paid work in the work status equation.

11. The excluded variable we use in the endogenous equation is the variation in GDP occurring in the year in which the individual has entered the labor market.

12. Related results are available upon request.

13. For the sake of brevity, we do not report the estimates of the selection equation by gender. They are available upon request.

\section{References}

Ahmed, S. (2015), "Dynamics and diversity: how are religious minorities faring in the labour market in Bangladesh?”, MPRA Paper No. 75153.

Alam, M. and Zanariah, N. (2012), "Mothers' perception on the impact of employment on their children: working and non-working mothers", IAMURE International Journal of Social Sciences, Vol. 2, pp. 113-131.

Arulampalam, W., Booth, A.L. and Taylor, M.P. (2000), "Unemployment persistence", Oxford Economic Papers, Vol. 52 No. 1, pp. 24-50. 
Asadullah, M.N. and Talukder, F. (2019), "The paradox of the contented female workerEvidence from Bangladesh's ready-made garments sector”, International Journal of Manpower, Vol. 40 No. 4, pp. 800-814.

Asian Development Bank (2015), Challenges and Opportunities for Skills Development in Asia: Changing Supply, Demand and Mismatches, ADB, Manila.

Baert, S., Cockx, B. and Verhaest, D. (2013), "Overeducation at the start of the career: stepping stone or trap?”, Labor Economics, Vol. 25 No. C, pp. 123-140.

Bongaarts, J., Blanc, A.K. and McCarthy, K.J. (2019), “The links between women's employment and children at home: variations in low- and middle-income countries by world region”, Population Studies, Vol. 73 No. 2, pp. 149-163.

Burgess, S., Propper, C., Rees, H. and Shearer, A. (2003), "The class of 1981: the effects of early career unemployment on subsequent unemployment experiences”, Labor Economics, Vol. 10 No. 3, pp. 291-309.

Contini, B., Pacelli, L. and Villosio, C. (1999), "Short employment spells in Italy, Germany and the UK: testing the port of entry hypothesis", CEP Discussion papers dp0426, Centre for Economic Performance, LSE.

Elder, S. and Kring, S. (2016), Young and Female - A Double Strike? Gender Analysis of School-ToWork Transition Surveys in 32 Developing Economies, Work4Youth Publication Series No. 32, ILO, Geneva.

Green, F. and Montgomery, S.M. (1998), “The quality of skill acquisition in young workers' first job”, Labour, Vol. 12 No. 3, pp. 473-487.

Heath, R. and Mobarak, A.M. (2015), "Manufacturing growth and the lives of Bangladeshi women", Journal of Development Economics, Vol. 115, pp. 1-15.

ILO (2016), Bangladesh, SWTS Country Brief, International Labour Office, Geneva.

ILO (2018a), "Empowering women working in the informal economy", 2nd Meeting of the Global Commission on the Future of Work, 15-17 February 2018.

ILO (2018b), World Employment and Social Outlook: Trends for Women 2018 - Global Snapshot, ILO, Geneva.

ILO (2018c), Asia-Pacific Employment and Social Outlook: Advancing Decent Work for Sustainable Development, ILO, Geneva.

Khatun, F., Rahman, M., Bhattacharya, D., Moazzem, K.G. and Shahrin, A. (2008), "Gender and trade liberalization in Bangladesh: the case of ready-made garments", CPD Research Monograph Series n. 2.

Lehmann, H. and Pignatti, N. (2018), "Informal employment relationships in the labor market: is there segmentation in Ukraine?”, Journal of Comparative Economics, Vol. 46, pp. 838-857.

Lewis, W.A. (1954), "Economic development with unlimited supplies of labor", The Manchester School, Vol. 22 No. 2, pp. 139-191.

Maloney, W.F. (2004), “Informality revisited”, World Development, Vol. 32 No. 7, pp. 1159-1178.

Manacorda, M., Rosati, F.C., Ranzani, M. and Dachille, G. (2017), "Pathways from school to work in the developing countries”, IZA Journal of Development and Migration, Vol. 6 No. 1, pp. 1-40.

McKay, A., Mussida, C. and Veruete, L. (2018), "The challenge of youth employment in Asia: lessons from four fast-growing economies”, The World Economy, Vol. 41, pp. 1045-1067.

Millán, J.M., Congregado, E. and Román, C. (2014), "Persistence in entrepreneurship and its implications for the European entrepreneurial promotion policy”, Journal of Policy Modeling, Vol. 36 No. 1, pp. 83-106.

Mostafa, R. and Klepper, S. (2018), "Industrial development through tacit knowledge seeding: evidence from the Bangladesh garment industry”, Management Science, Vol. 64 No. 2, pp. 613-632.
First job affect current youth working status 
IJM

42,6

Pastore, F. (2010), “The gender gap in early career in Mongolia”, International Journal of Manpower, Vol. 31 No. 2, pp. 188-207.

Pieters, J. (2013), "Youth employment in developing countries", IZA Research Report n. 58.

Reize, F. (2001), "FIML estimation of a bivariate probit selection rule: an application on firm growth and subsidization”, ZEW Discussion paper n. 01-13.

Roodman, D. (2011), "Fitting fully observed recursive mixed-process models with cmp", STATA Journal, Vol. 11 No. 2, pp. 159-206.

Sarkar, S., Sahoo, S. and Klasen, S. (2019), "Employment transitions of women in India: a panel analysis", World Development, Vol. 115, pp. 291-309.

Scherer, S. (2004), "Stepping-stones or traps?: the consequences of labour market entry positions on future careers in west Germany, Great Britain and Italy", Work, Employment and Society, Vol. 18 No. 2, pp. 369-394.

Sparreboom, T. and Staneva, A. (2014), Is Education the Solution to Decent Work for Youth in Developing Economies? Identifying Qualifications Mismatch from 28 School-to-Work Transition Surveys, ILO, Geneva.

United Nations (2015), "Transforming our world: the 2030 agenda for sustainable development A/RES/70/1", United Nations, available at: sustainabledevelopment.un.org.

Verhaest, D. and Omey, E. (2013), "The relationship between formal education and skill acquisition in young workers' first job", The Manchester School, Vol. 81 No. 4, pp. 638-659.

World Bank (2018), World Bank Statistics, World Bank, Washington, District Columbia. 
Table A1

The impact of employment entry on current work outcomes accounting for endogeneity of entry status 
IJM
42,6

1042

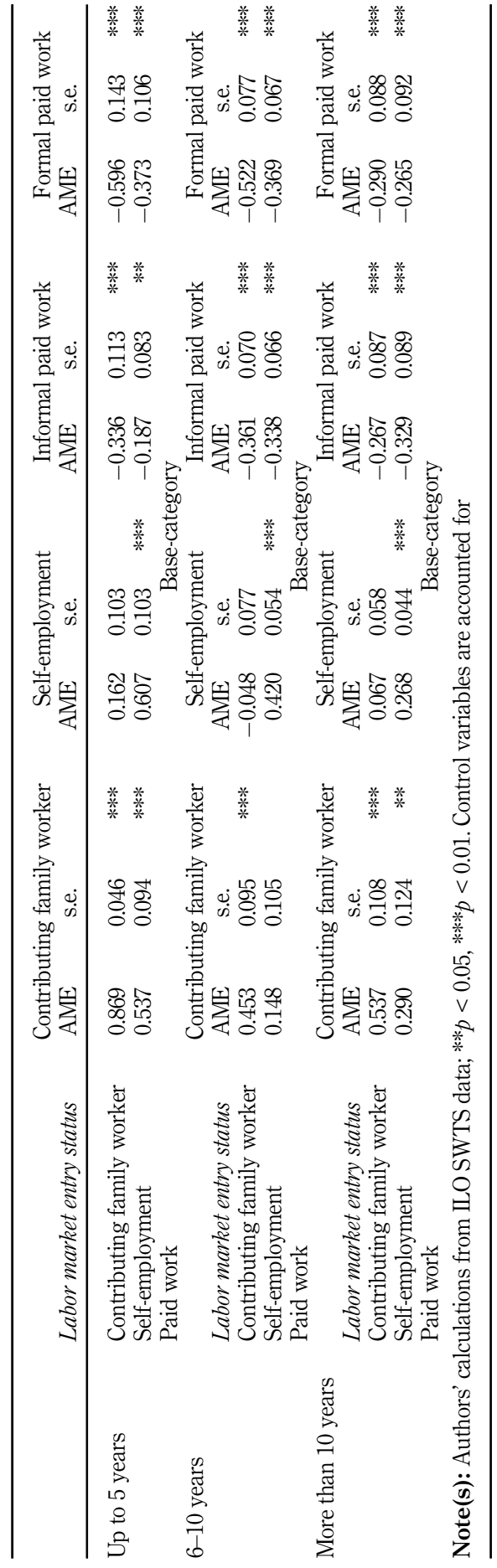

Table A2.

The impact of

employment entry on

current work outcomes by years from entering the labor market

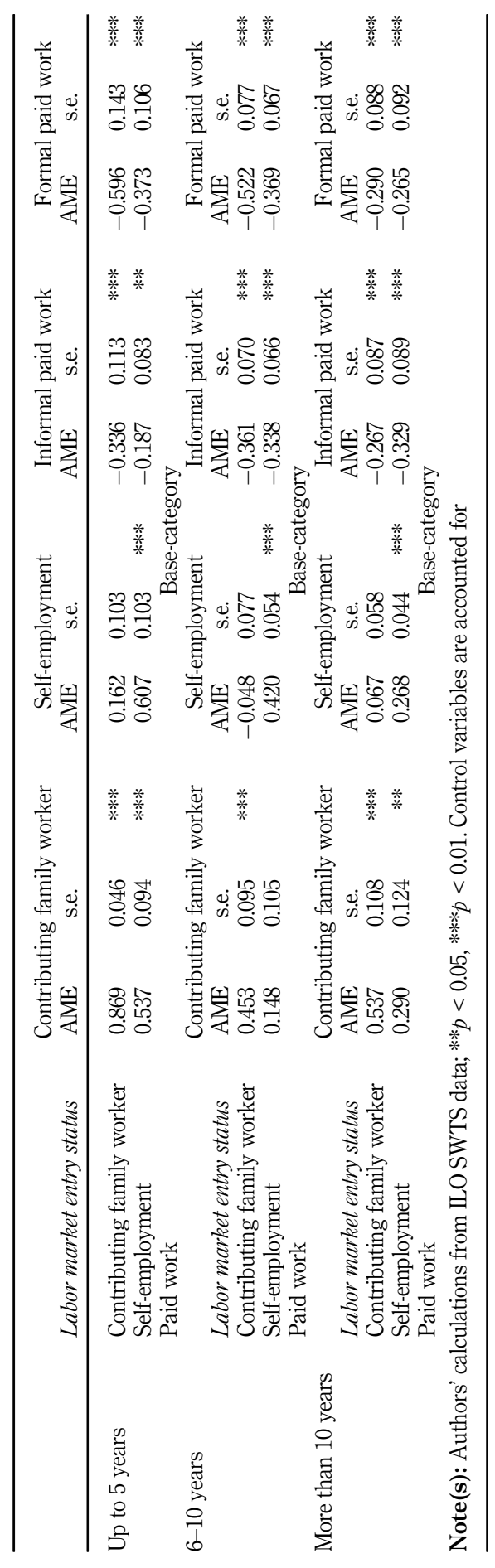


Table A3. The impact of employment entry on current work outcomes for youths from 25 to 29 years of age 
IJM

42,6

Appendix 2

1044

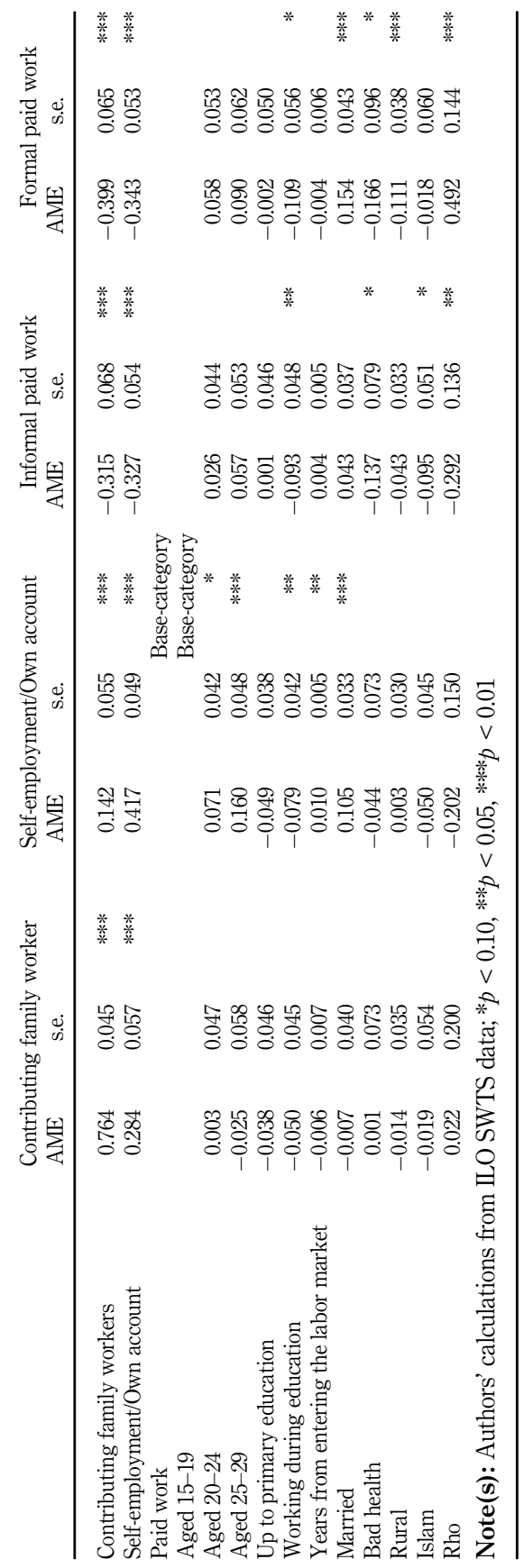

Table A4.

The impact of

employment entry on

current work

outcomes: males 
First job affect current youth

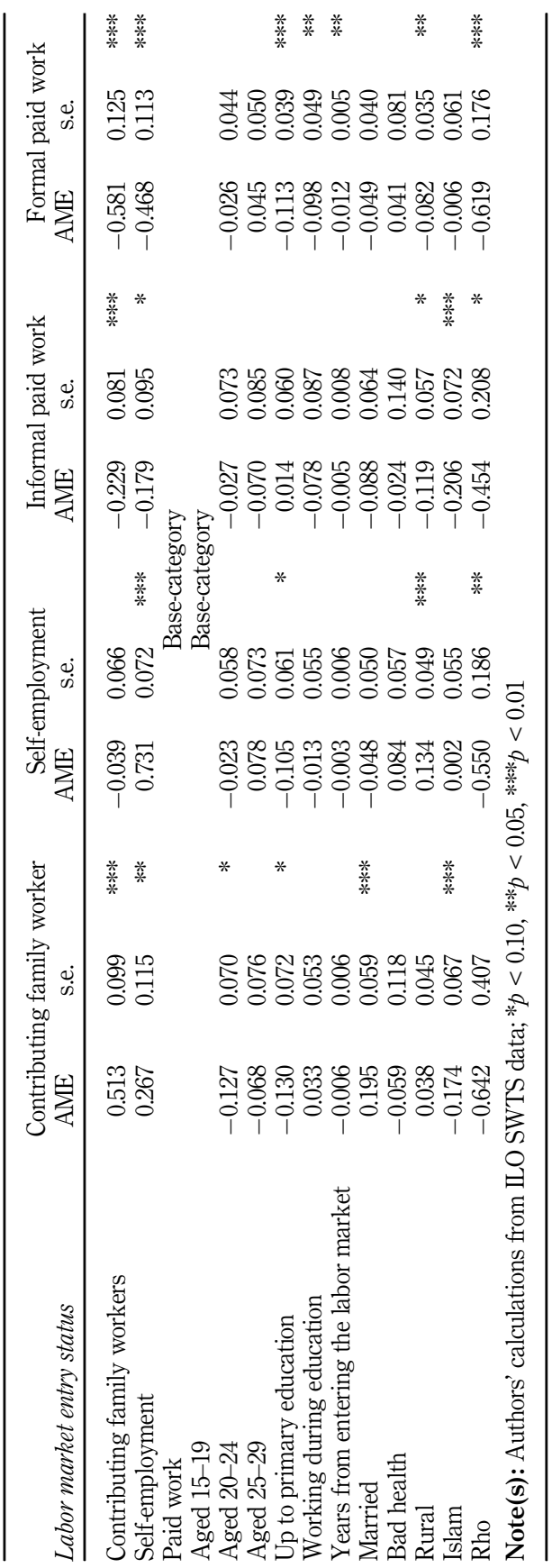
working status

1045

Table A5. The impact of employment entry on current work outcomes: females 
About the authors

42,6

Chiara Mussida is an associate professor of Economic Policy at the Università Cattolica del Sacro Cuore (Piacenza). Her research interests include labor economics, gender inequality, income inequality and microeconometrics. She published in international and national journal, such as Labor Economics, Journal of Income Inequality, Journal of Policy Modeling, Regional Studies, Empirical Economics.

Dario Sciulli (Ph.D University of Tor Vergata) is an associate professor of Economic Policy at the University of Chieti-Pescara (Italy). He held visiting positions at the Universidad Carlos III Madrid, University of York, VU University of Amsterdam and Universidad de Salamanca. His research interests include labor economics, economics of disability and applied microeconometrics and published in international journals, such as Review of Economics of the Household, Journal of Behavioral and Experimental Economics, B.E. Journal of Economic Analysis and Policy, Journal of Policy Modeling, International Journal of Manpower, Journal of Labor Research. Dario Sciulli is the corresponding author and can be contacted at: d.sciulli@unich.it

For instructions on how to order reprints of this article, please visit our website: www.emeraldgrouppublishing.com/licensing/reprints.htm Or contact us for further details: permissions@emeraldinsight.com 